\title{
Description of a new experimental model skin flap for studying skin viability in rats ${ }^{1}$
}

\author{
Cristina Pires Camargo ${ }^{\mathrm{I}}$, Nelson Fontana Margarido ${ }^{\mathrm{II}}$, Eduardo Guandelini' ${ }^{\mathrm{III}}$, Guilherme Alexandre Barrucci Vieira ${ }^{\mathrm{III}}$, Alfredo \\ Luiz Jacomo ${ }^{\mathrm{IV}}$, Rolf Gemperliv
}

IFellow PhD degree, Postgraduate Program in Medicine Surgical Clinics, School of Medicine, University of Sao Paulo (USP), Sao Paulo-SP, Brazil. Surgical procedures, acquisition of data, manuscript writing.

IEmeritus Professor, Department of Anatomy, School of Medicine, USP, Sao Paulo-SP, Brazil. Critical revision.

III Graduate student, School of Medicine, USP, Sao Paulo-SP, Brazil. Surgical procedures.

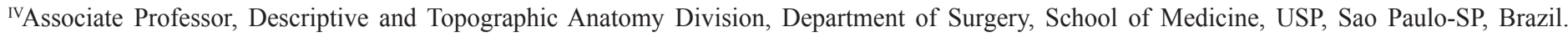
Manuscript writing, critical revision.

vAssociate Professor, Division of Plastic Surgery, School of Medicine, USP, Sao Paulo-SP, Brazil. Conception and design of the study, manuscript writing, critical revision.

\section{ABSTRACT}

PURPOSE: To describe a new experimental flap for studying skin viability in rats.

METHODS: Twenty male Wistar rats weighing between 250-300g were divided into two groups: group A - McFarlane technique, a $4 \times 10 \mathrm{~cm}$ flap was used (McFarlane); and in group B modified McFarlane technique, a $3 \times 10 \mathrm{~cm}$ flap was used. Seven days later, the animals were sacrificed and the area of necrosis was evaluated in both groups.

RESULTS: Group A presented necrosis in 3\% of the total area of the flap (CI: 0.01-0.05), Group B presented necrosis in 37\% of the total area of the flap (CI: 0.29-0.46), ( $<<0.001)$.

CONCLUSION: The modified McFarlane flap presented a larger area of necrosis and could be an adequate experimental model of skin flap viability.

Key words: Surgical Flaps. Necrosis. Models, Animal. Rats. 


\section{Introduction}

Flaps have been used in plastic surgery since 800 b.C. Skin flaps are basically employed for the repair of large wound defects. The techniques of skin flaps are well established and they vary according to the location of the wound and the extension of the defect ${ }^{1}$. The most feared complication of a skin flap is a significant area of necrosis causing the failure of the surgical procedure. The estimated frequency of necrosis of skin flaps varies between 2 and $20 \%{ }^{1,2}$.

Bearing this fact in mind, a reproducible and effective experimental model of necrosis of skin flaps would be useful to evaluate different substances and devices that might increase the viability of flaps ${ }^{3,4}$.

McFarlane et al..$^{5}$ described the dorsal cutaneous flap in rats. Since then this experimental model has been adopted as the gold standard in studies evaluating the viability of axial flaps. The original dimensions described in McFarlane's et al. study were of $4 \mathrm{~cm}$ across the base by $10 \mathrm{~cm}$ in length (i.e. a 1:2.5 ratio), taking the scapulae as the base of the flap. In the original study, the authors described necrosis of $25-50 \%$ of the flap length.

However, in the literature several studies have cited this technique as a reference, but with different dimensions. Flaps measuring $2 \times 8 \mathrm{~cm}^{6}, 3 \times 7 \mathrm{~cm}^{7}$, and $3 \times 9 \mathrm{~cm}^{8}$ have been described and attributed to McFarlane, casting doubt on the results of the original description. In addition, the location of the base described as cranial (at the level of the scapulae) has also not been uniform ${ }^{6-8}$.

In the light of the lack of consensus, and because of the need for an effective and reproducible experimental $\operatorname{model}^{9}$ of skin flap necrosis, we decided to conduct a comparative study between the flap described by McFarlane and a skin flap with different dimensions.

\section{Methods}

This project was approved by the Ethics Committee, School of Medicine, University of Sao Paulo. All the experiments complied with regulations on animal experimentation described by the Council for international Organization of Medical Sciences (CIOMS).

Twenty male Wistar rats weighing between 250-300 g were divided into two groups:

- Group A (10 animals) - McFarlane flap (4 x 10cm);

- Group B (10 animals) - modified flap (3 x 10cm).

All the animals were housed in separate cages, with $a d$ libitum offer of food and water, $25^{\circ} \mathrm{C}$ temperature and controlled day and night cycling.
The animals were anesthetized by inhalation of a mixture of $20 \%$ isoflorane and oxygen and positioned in ventral decubitus.

The dorsal region was shaved. Aqueous $0.5 \%$ chlorhexidine was used for antisepsis of the surgical field.

\section{Flap design}

\section{Group A - McFarlane}

Starting from the rat's midline, two equidistant points were marked out using a marker pen, $2.0 \mathrm{~cm}$ on each side of the midline, at the level of the base of the scapulae. This was defined as the base of the flap. The length of the flap was marked out as two parallel lines $10 \mathrm{~cm}$ long, starting from the previously established base. Thus, the flap final dimensions were 4 x 10cm (Figure 1A).

Group B - Modified flap

Starting from the rat's midline, a flap was delimited by marking out points $1.5 \mathrm{~cm}$ on each side of the midline, at the level of the base of the scapulae, and this was taken as the base of the flap. The remaining markings were the same as described for group A (Figure 1B).

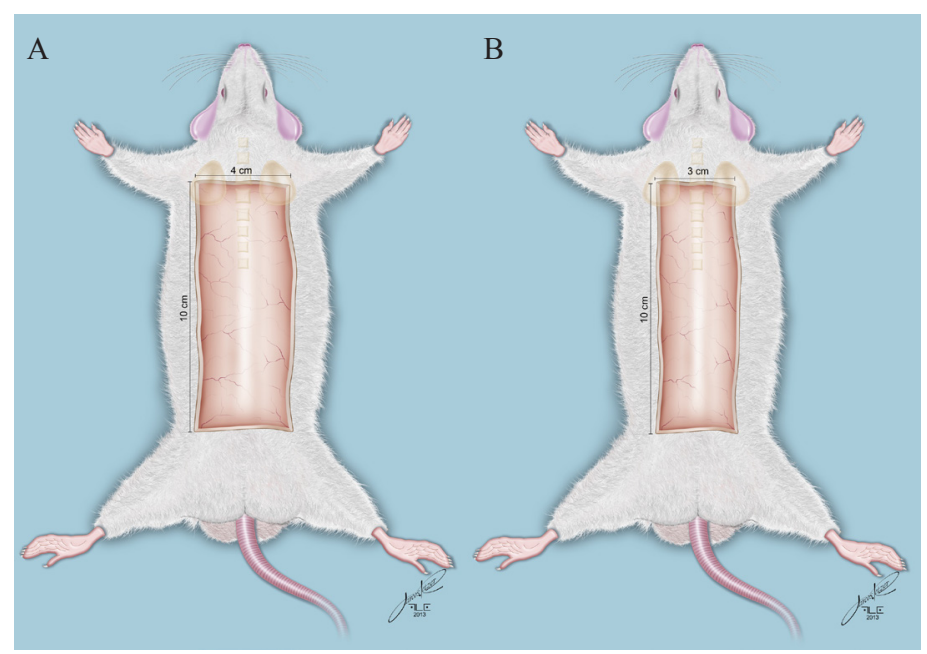

FIGURE 1 - A. McFarlane, with 4 x $10 \mathrm{~cm}$ dimensions. B. Modified dorsal skin flap, with $3 \times 10 \mathrm{~cm}$ dimensions.

\section{The flap dissection and suture}

After demarcating the flap, the skin was incised. The flap was raised by dissecting the areolar tissue at the level of the panniculus carnosus and deep fascia of the rat's dorsal musculature, as far as the interscapular base.

The flap was repositioned in its original position and was sutured with 4-0 monofilament nylon single stitches at $0.5 \mathrm{~cm}$ intervals. 
After recovery from anesthesia, the animals were kept in separate cages with ad libitum offer of food and water for seven days. Paracetamol (40mg) was added to $100 \mathrm{ml}$ of water, in conformity with the recommendations for laboratory animal care. All the animals were observed daily.

\section{Evaluation of skin flap viability}

On the seventh postoperative day, the flaps were photographed with a ruler in centimeters that was placed on the animal back. This image was then digitalized using the Image $\mathrm{J}^{\mathbb{B}}$ software (NIH; http://rsbweb.nih.gov/ij). All the photographs were calibrated for readings in $\mathrm{mm}^{2}$. By using the area function of the software it was possible to measure the total area of the flap and the area of necrosis.

Viable skin was defined as a pink, warm, soft on touch tissue (Figure 2A). Necrotic area was defined as a brown-black, cold and hard to manipulate skin (Figure 2B).

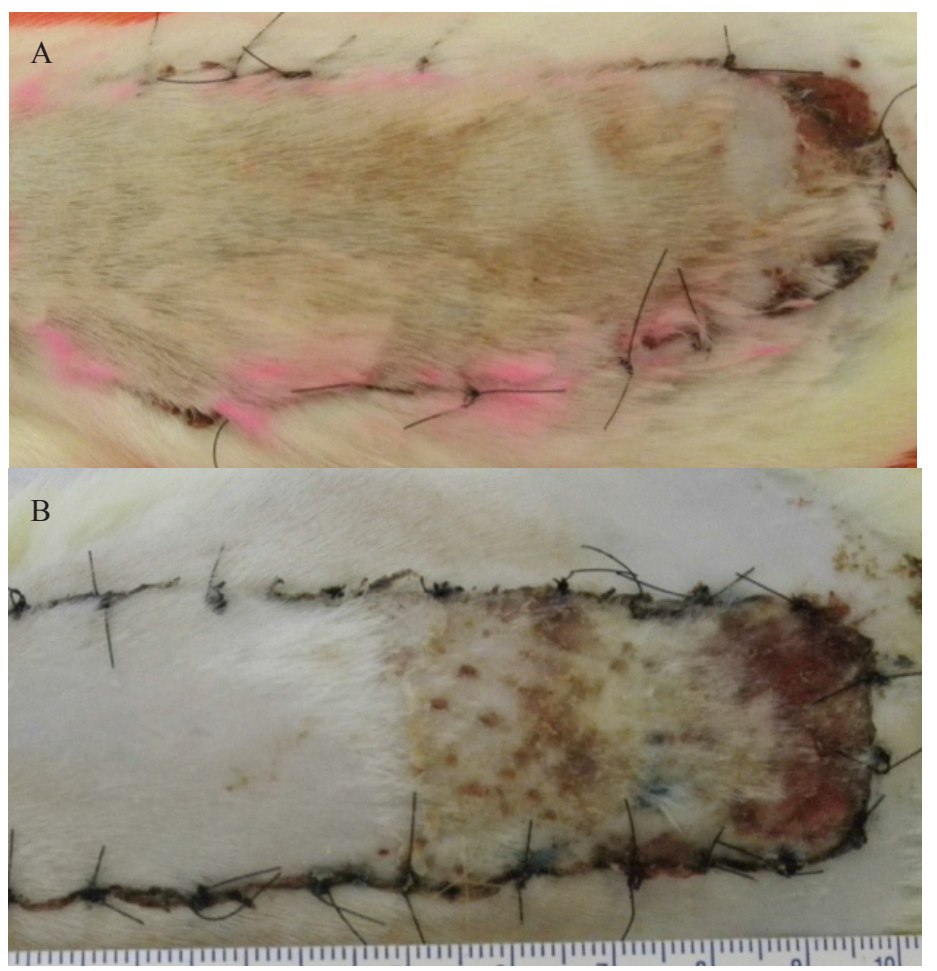

FIGURE 2 - A. Viable flap with a small area of necrosis (arrows); B. Flap with a significant area of necrosis (arrows).

Excel software (Windows $7^{\circledR}$ ) was employed to calculate the area of necrosis to the total area ratio.

\section{Statistical analysis}

The necrosis/total flap area ratio was compared between groups A and B by using the Mann-Whitney test. The tests were calculated using the IBM SPSS statistical software (Statistical
Package for the Social Sciences), version 21.0. $\mathrm{p}<0.05$ was considered significant.

\section{Results}

After measuring the areas on the flap, the total area, area of necrosis and ratio of the area of necrosis/total area were calculated for both groups, as shown in Tables 1 and 2 .

TABLE 1 - McFarlane flap (group A): total area, area of necrosis and ratio of the area of necrosis/total area.

\begin{tabular}{lccc}
\hline Animal & $\begin{array}{c}\text { Total } \\
\text { Area }\end{array}$ & Area of Necrosis & $\begin{array}{c}\text { Necrosis Area / Total } \\
\text { Area }\end{array}$ \\
\hline 1 & 3632.507 & 167.851 & 0.046 \\
2 & 3538.111 & 157.429 & 0.044 \\
3 & 5220.246 & 245.206 & 0.047 \\
4 & 3382.465 & 263.879 & 0.078 \\
5 & 5129.246 & 0 & 0 \\
6 & 5231.855 & 0 & 0 \\
7 & 3290.583 & 143.975 & 0.044 \\
8 & 4098.522 & 0 & 0 \\
9 & 4223.094 & 0 & 0 \\
10 & 4429.851 & 0 & 0 \\
\hline
\end{tabular}

TABLE 2 - Modified flap (group B): total area, area of necrosis and ratio of the area of necrosis/total area.

\begin{tabular}{ccccc}
\hline Animal & $\begin{array}{c}\text { Total } \\
\text { Area }\end{array}$ & $\begin{array}{c}\text { Necrosis } \\
\text { Area }\end{array}$ & Epitheliolysis & $\begin{array}{c}\text { Necrosis } \\
\text { Area/ Total } \\
\text { Area }\end{array}$ \\
\hline 1 & 3297.828 & 1102.385 & 0 & 0.335 \\
2 & 2675.927 & 1039.013 & 0 & 0.388 \\
3 & 2458.671 & 1427.141 & 0 & 0.580 \\
4 & 2919.654 & 734.07 & 309.004 & 0.251 \\
5 & 2717.011 & 932.382 & 598.465 & 0.343 \\
6 & 2891.185 & 1423.789 & 0 & 0.492 \\
7 & 2726.746 & 1057.967 & 0 & 0.388 \\
8 & 3137.027 & 551.826 & 599.139 & 0.176 \\
9 & 2756.083 & 1239.072 & 178.498 & 0.449 \\
10 & 2717.011 & 932.382 & 598.465 & 0.343 \\
\hline
\end{tabular}

The mean ratios of the area of necrosis/total area were $3 \%$ and $37 \%$ for the McFarlane and modified flap groups respectively (Figure 3). The comparison between groups is demonstrated in Table 3. 


\section{MEAN AREA OF NECROSIS (\%) IN TWO GROUPS}

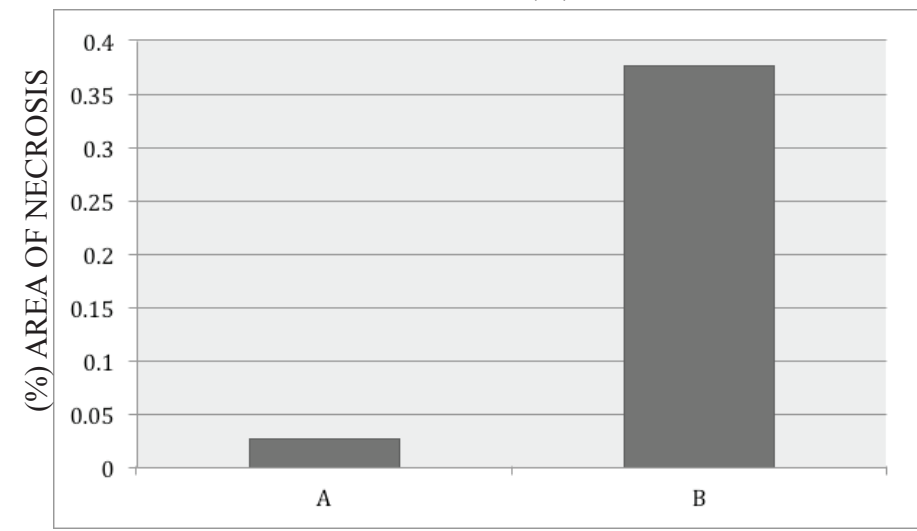

FIGURE 3 - Graphic showing McFarlane flap (A) and new flap (B).

TABLE 3 - Ratio between the area of flap necrosis and the total area, using the Mann-Whitney test.

\begin{tabular}{ccccc}
\hline & Mean & $\begin{array}{c}\text { Standard } \\
\text { deviation }\end{array}$ & $\begin{array}{c}\text { Standard } \\
\text { error }\end{array}$ & $\mathbf{9 5 \% ~ C I ~}$ \\
\hline $\begin{array}{c}\text { Group A } \\
(\mathbf{n}=\mathbf{1 0})\end{array}$ & 0.03 & 0.003 & 0.001 & $0.01-0.05$ \\
$\begin{array}{c}\text { Group B* } \\
(\mathbf{n}=10)\end{array}$ & 0.37 & 0.12 & 0.004 & $0.29-0.46$ \\
\hline
\end{tabular}

$95 \% \mathrm{CI}=95 \%$ confidence interval

* A vs $B=p<0.001$

\section{Discussion}

Although the flap described by McFarlane et al..$^{5}$ is considered the gold standard for experimental studies on skin viability, it has been observed that there is not uniformity in this technique. Based on the literature, we noted that several studies cited this technique as a reference, but many of them had not used the dimensions established by McFarlane. In addition, it was seen that several authors who had used the original design $(4 \times 10 \mathrm{~cm})$ described areas of necrosis which varied from $10 \%{ }^{10}$ to $60 \%{ }^{11}$.

Another point to be considered is that there was some variation in the location of the base among the flaps attributed to McFarlane et al. ${ }^{5}$. Some were elevated with the base in the caudal part of the animal's back ${ }^{6}$, which others had the base in the cranial part, at the level of the scapulae ${ }^{7}$.

In view of the lack of consensus, we decided to conduct a study on a new flap with $3 \times 10 \mathrm{~cm}$ dimension, with a cranial base, comparing the area of necrosis at the seventh postoperative day with the original flap proposed by McFarlane et al. ${ }^{5}$

The cranial base was chosen because the base of the animal's scapulae forms a rigid anatomical parameter. Moreover, in all dissections, it was noted that in this anatomical position there is a small vascular bundle that follows along the length of this flap, which makes it an axial flap.

However, this positioning can be criticized. Briggs et $a l .{ }^{12}$ reported that the position of the forelimbs caused variations in the location of the flap when the base was positioned at the level of the scapulae. Depending on the angle formed between the forelimbs and trunk, the base of the flap could change because the scapulae could shift up to one centimeter. This was not confirmed in the present study because the animal was positioned on a wooden board that was appropriate for this purpose and the animal's forelimbs were kept fixed, i.e. always at the same angle, without changing the level of the scapulae.

Following these simple rules, we can say that all the flaps were drawn up and the incisions were made correctly and in a reproducible manner because rigid anatomical parameters were employed.

We utilized the same parameters as those describe by Gemperli et al. ${ }^{13}$ to define the macroscopic criteria for flap viability. Viable area was defined as a pink, warm and soft-to- touch skin on the $7^{\text {th }}$ postoperative day. Necrotic area was defined as a brownblack, rigid-to-touch skin. And the area that was between these two presentations was classified as epithelyosis. For statistical purpose, only necrotic and total areas were evaluated. In clinical practice, most of epithelyosis areas regenerate with conservative measures such as.

In this study, necrosis was observed on almost $40 \%$ of the area of the modified flap, more than 10x when compared with the necrosis observed in the McFarlane group. These findings confirm that the flap described by McFarlane et al..$^{5}$, in the form that was proposed, does not produce a significant area of necrosis. Therefore the McFarlane flap does not seem to be suitable for studying strategies that might change the viability of dorsal skin flaps. On the other hand, the modified flap with a shorter cranial base gave rise to an area of necrosis that was compatible with the expectations for an experimental model that would be suitable for studying skin viability.

\section{Conclusion}

The modified flap with dimensions of $3 \times 10 \mathrm{~cm}$, with a cranial base, is more appropriate for experimental studies for the viability of skin flaps.

\section{References}

1. Frederick FW, Sweeny L, Carroll WR, Peters GE, Rosenthal EL. Outcomes in head and neck reconstruction by surgical site and donor site. Laryngoscope. 2013;123(7):1612-7. 
2. Lebas D, Wiart T, Gros C, Modiano P. Use of a rhomboid flap to repair temporal and frontotemporal cutaneous defects: 11 cases. An Dermatol Venereal. 2013;140:170-5.

3. Acevedo-Bogado CE, Bins-Ely J, d'Acampora AJ, Neves RD. Efeito da hialuronidase na sobrevida de retalhos cutâneos em ratas. Acta Cir Bras. 2002;17(1):14-6.

4. Reichner DR, Scholz T, Vanderkam VM, Gutierrez S, Steward E, Evans GR. Laser flap delay: comparison of Erbium: YAG and CO2 lasers. Am Surg. 2003;69(1):69-72.

5. McFarlane RM, DeYoung G, Henry RA. The design of pedicle flap in the rat to study necrosis and its prevention. Plast Reconstr Surg. 1965;35(2):177-82.

6. Oh M, Chang H, Minn KW. The effects of tadalafil on axial-pattern skin flap survival in rats. Dermatol Surg. 2008;34(5):626-30.

7. Barral SM, Araujo ID, Vidigal PVT, Mayrink CAC, Araujo AD, da Costa PR. Effects of sildenafil on the viability of random skin flaps. Acta Cir Bras. 2011;26(4):314-9.

8. Lin DS, Zheng X, Li ZJ, Zhang YP, Wang AY, Xie XG, Gao WY Effect of hirudin on random skin flap survival in rats. Zhonghua Zheng Xing Wai Ke Za Zhi. 2011;27(1):35-9.

9. Moura TD, Marques Ade A, Bernal SO, Gagliocca GD, Gemperli R, Ferreira MC. Study of the effect of streptokinase and allopurinol in island skin flaps submitted to prolonged ischemia: experimental study in rats. Rev Assoc Med Bras. 2009;55(5):601-5.

10. Tosun Z, Bite U. A comparative study of the influence of smoking on skin flap survival in pregnant rats. Br J Plastic Surg. 2005;58(6):812-6.

11. Abla LEF, Gomes HG, Percario S, Ferreira LM. Acetylcysteine in random skin flap in rats. Acta Cir Bras. 2005;20(2):121-3.
12. Briggs PC. The McFarlane flap. Plast Reconstr Surg. 1987;80(3):472-3.

13. Gemperli R, Munhoz AM. The influence of type of vascular pedicle occlusion on the viability of skin Island flaps. A postoperative quantitative assessment of flap survival in an experimental model in rats. Acta Cir Bras. 2013;28(7):487-93.

Correspondence:

Cristina Pires Camargo

Avenida Brigadeiro Luiz Antonio, 4161

01402-002 São Paulo - SP Brasil

Tel.: (55 11)3884-7599

consultoriodracristina@gmail.com

Received: Nov 18, 2013

Review: Jan 20, 2014

Accepted: Feb 21, 2014

Conflict of interest: none

Financial source: none

${ }^{1}$ Research performed at Laboratory of Descriptive and Topographic Anatomy Division, Department of Surgery, School of Medicine, University of Sao Paulo (USP), Brazil. Part of PhD degree thesis, Postgraduate Program in Medicine Surgical Clinics. Tutor: Rolf Gemperli. 